\title{
Formation of Titanium Nitride Nanoparticles within Mesoporous Silica SBA-15
}

\author{
Han-Sheng Hsueh, ${ }^{\dagger}$ Cheng-Tzu Yang, ${ }^{\dagger}$ Jeffrey I. Zink, ${ }^{\dagger}$ and Michael H. Huang*, ${ }^{\dagger}$ \\ Department of Chemistry, National Tsing Hua University, Hsinchu 30013, Taiwan, and \\ Department of Chemistry and Biochemistry, University of California, Los Angeles, California 90095
}

Received: September 18, 2004; In Final Form: December 18, 2004

\begin{abstract}
We report the first synthesis of titanium nitride (TiN) nanoparticles inside the nanoscale channels of mesoporous silica SBA-15. The TiN precursor, $\mathrm{Ti}\left(\mathrm{NMe}_{2}\right)_{4}$ in toluene, was incorporated into the methyl group-modified channels of the SBA-15 powder. The functionalization of pore surfaces with methyl groups generates hydrophobic surfaces that facilitate impregnation with $\mathrm{Ti}\left(\mathrm{NMe}_{2}\right)_{4}$ and minimizes reactions between the TiN precursor and the hydroxyl groups on the surface of SBA-15. Formation of TiN nanoparticles inside the mesoporous channels of SBA-15 was carried out by subsequent ammonolysis at high temperatures (700$750{ }^{\circ} \mathrm{C}$ ). The final products have been characterized by TEM and EELS images, powder XRD patterns, FTIR spectra, UV-vis absorption spectra, and nitrogen adsorption isotherm measurements to confirm the presence and distribution of TiN nanoparticles in the SBA-15 samples.
\end{abstract}

\section{Introduction}

Periodic mesoporous silica materials, such as MCM- $41,{ }^{1}$ MCM- $48,{ }^{2}$ and SBA- $15,{ }^{3}$ provide the templates for the formation of incorporated nanoparticles and nanowires. The pore diameters of these mesoporous materials dictate the sizes of the embedded particles and the diameters of the incorporated nanowires. Formation of nanowires by the template approach is a useful synthesis route for the growth of metal and semiconductor nanowires. The incorporated nanoparticles may also have interesting catalytic, optical, and magnetic properties. ${ }^{4-8}$ Hence the growth of metal and semiconductor nanomaterials in mesoporous silica has been an active area of research in recent years. Most of the studies involve the formation of metal nanoparticles and nanowires, such as $\mathrm{Au}, \mathrm{Ag}, \mathrm{Pt}, \mathrm{Pd}$, and $\mathrm{Ti}$, within the nanoscale channels of mesoporous silica powder. ${ }^{8-20}$ More recently, a number of studies have been directed at the synthesis of metal nanowires and nanoparticles in mesoporous silica films. ${ }^{21-23}$ In addition to studies on the growth of singleelement metal nanoparticles and nanowires in mesoporous silica materials, several studies have explored the formation of binary systems such as GaN, CdS, CdSe, ZnS, and ZnO. ${ }^{5-7,23-28}$ These binary materials are all semiconductors that have potential applications in optoelectronics. Formation of binary compounds within mesoporous silica materials is mainly limited to the particle morphology.

With the single exception of the synthesis of quantumconfined $\mathrm{GaN}$ nanoparticles in MCM-41, ${ }^{5}$ the formation of nitride nanoparticles within mesoporous silica powder or films has not been studied. This might be due to the lack of simple nitride source reagents that can be introduced into the nanoscale channels of mesoporous silica materials. TiN is an interesting material to try to incorporate into the mesoporous silica materials. TiN has high hardness, a high melting point (2927 ${ }^{\circ} \mathrm{C}$ ) and a low sintering tendency that are beneficial for applications in high-temperature heterogeneous catalysis. ${ }^{29} \mathrm{TiN}$

\footnotetext{
* To whom correspondence should be addressed. E-mail: hyhuang@ mx.nthu.edu.tw.

National Tsing Hua University.

$\div$ University of California, Los Angeles.
}

thin films are also being used as diffusion barrier layers between $\mathrm{Si}$ and $\mathrm{Al}$, and have been applied as adhesion layers for chemically vapor-deposited tungsten in semiconductor fabrication processes. ${ }^{30}$ Here we describe the formation of TiN nanoparticles within the channels of SBA-15 powder. A titanium amide, tetrakis(dimethylamino)titanium or $\mathrm{Ti}\left(\mathrm{NMe}_{2}\right)_{4}$, was used as the TiN source. Both $\mathrm{Ti}\left(\mathrm{NMe}_{2}\right)_{4}$ and $\mathrm{Ti}\left(\mathrm{NEt}_{2}\right)_{4}$ have been used in the chemical vapor deposition of TiN films under ammonia flow at temperatures of $\sim 300-550{ }^{\circ} \mathrm{C}$, and thus should represent as suitable candidates for the preparation of TiN nanoparticles within mesoporous silica SBA-15. ${ }^{30,31} \mathrm{Py}-$ rolysis of the metal amide in the absence of ammonia may result in greater residual carbon content in the TiN films. ${ }^{31 a}$ Thus ammonolysis during the pyrolysis reaction of $\mathrm{Ti}\left(\mathrm{NMe}_{2}\right)_{4}$ was used in the present study.

\section{Experimental Section}

Mesoporous silica SBA-15 was prepared following the literature procedure with slight modification. ${ }^{3,8}$ A tri-block copolymer poly(ethylene oxide)-poly(propylene oxide)-poly(ethylene oxide), or $\mathrm{EO}_{20} \mathrm{PO}_{70} \mathrm{EO}_{20}$, was used as the template for the preparation of mesoporous SBA-15 powder. First, $2 \mathrm{~g}$ of $\mathrm{EO}_{20} \mathrm{PO}_{70} \mathrm{EO}_{20}$ was added to a beaker with $15 \mathrm{~g}$ of $\mathrm{H}_{2} \mathrm{O}$ with stirring at room temperature until the triblock copolymer has completely dissolved. A $60 \mathrm{~g}$ sample of $2 \mathrm{M} \mathrm{HCl}$ and $4.25 \mathrm{~g}$ of tetraethyl orthosilicate (TEOS) were then added. The mixture was stirred at $40{ }^{\circ} \mathrm{C}$ for several hours without the use of a cover over the beaker to produce finer powder particles. The mixture was transferred to a sealed container and was kept at $100{ }^{\circ} \mathrm{C}$ in an oven for $20 \mathrm{~h}$. The resulting white precipitate was filtered and dried at $80{ }^{\circ} \mathrm{C}$. Finally, the template was removed by calcination at $550{ }^{\circ} \mathrm{C}$ for $3 \mathrm{~h}$ to give fine mesoporous SBA-15 powder.

The hydrophilic nature of the pore channels of SBA-15 due to the presence of silanol groups $(\mathrm{Si}-\mathrm{OH})$ can be modified with methyl groups to make them more hydrophobic. A more hydrophobic intrachannel surface may facilitate the impregnation of $\mathrm{Ti}\left(\mathrm{NMe}_{2}\right)_{4}$ in the mesoporous channels. Another important consideration in trying to modify the channel surface with 


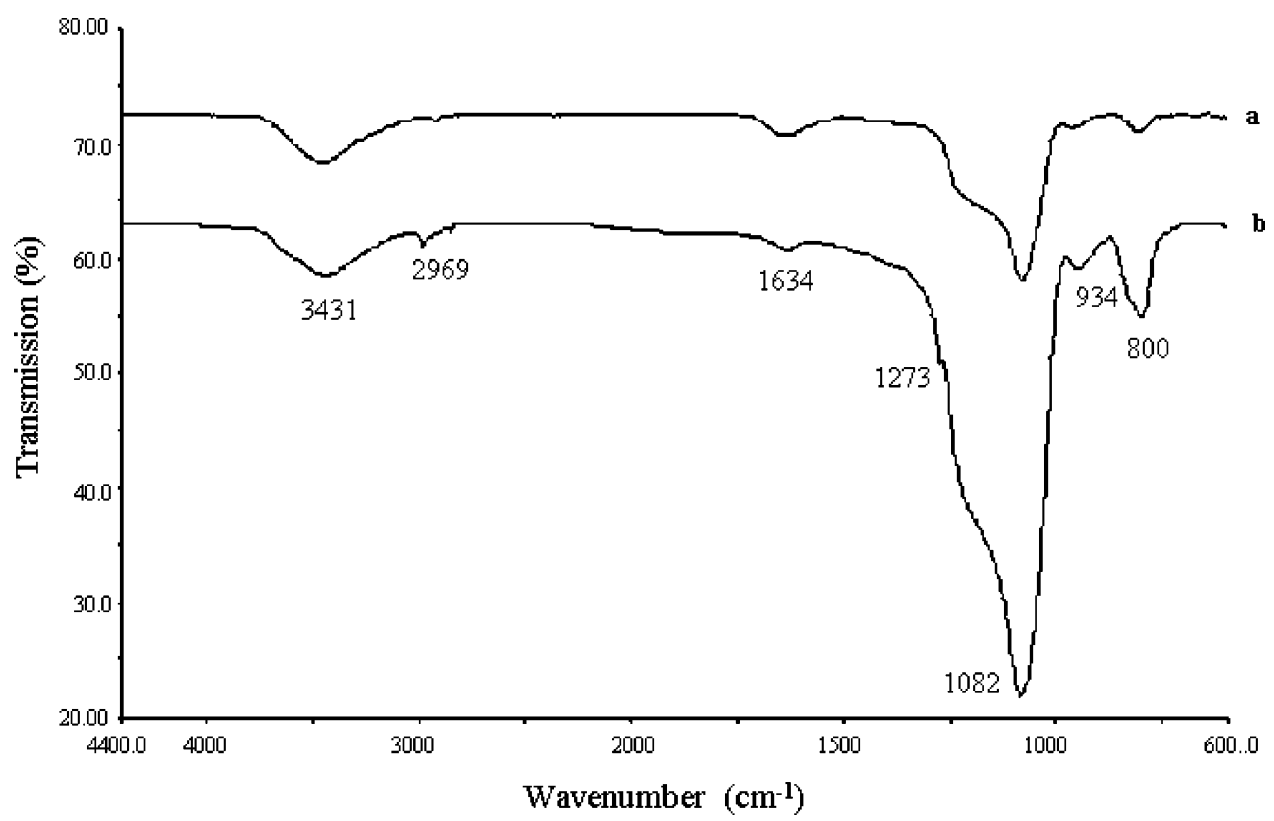

Figure 1. FTIR spectra of (a) calcined SBA-15 powder and (b) methyl group-functionalized SBA-15.

methyl groups is to minimize reactions between the TiN precursor and the surface silanol groups. Titanium isopropoxide incorporated into the channels of SBA-15 powder has been reported to react with the silica wall silanol groups and form a titanium dioxide anatase film. ${ }^{19}$ Before surface modification with the methyl groups, the calcined SBA-15 was refluxed in water for $1 \mathrm{~h}$ and then heated in a vacuum at $100{ }^{\circ} \mathrm{C}$ to remove water. ${ }^{12}$ A $0.2 \mathrm{~g}$ sample of the rehydrated SBA-15 was added to $30 \mathrm{~mL}$ of toluene. Then $20 \mathrm{~mL}$ of methyltriethoxysilane, prepared with 50 wt $\%$ of ethanol, was added to the toluene solution. The resulting mixture was stirred at room temperature for 1 day. After refluxing the mixture at $80{ }^{\circ} \mathrm{C}$ for $6 \mathrm{~h}$, the functionalized SBA-15 (Me-SBA-15) was washed with toluene and ethanol and dried in air.

The final step of the process is the impregnation of $\mathrm{Ti}\left(\mathrm{NMe}_{2}\right)_{4}$ and then formation of TiN nanoparticles in Me-SBA-15. A 0.02 $\mathrm{g}$ sample of the Me-SBA-15 powder was mixed with a solution of $0.2 \mathrm{~g}$ of $\mathrm{Ti}\left(\mathrm{NMe}_{2}\right)_{4}$ and $2 \mathrm{~g}$ of toluene. The mixture was stirred under nitrogen flow for $24 \mathrm{~h}$. After that, the temperature was raised to $150{ }^{\circ} \mathrm{C}$ to remove toluene. To clean excess precursor from the external surface of SBA-15, $5 \mathrm{~mL}$ of toluene was added to the flask without exposure to air, and the solution was heated at $150{ }^{\circ} \mathrm{C}$ in a vacuum. This step was repeated several times. After washing, the temperature was raised from 150 to $400{ }^{\circ} \mathrm{C}$ and kept at this temperature for $2 \mathrm{~h}$ under flowing ammonia. To further increase the temperature for the formation of TiN, the powder was transferred from the flask into a tube furnace. Ammonia was allowed to flow inside the furnace quartz tube for $1 \mathrm{~h}$ to eliminate oxygen in the quartz tube before raising the furnace temperature. The powder sample was then heated to $700-750{ }^{\circ} \mathrm{C}$ for $1-6 \mathrm{~h}$. Black powder was obtained after cooling the furnace to room temperature. $\mathrm{Ti}\left(\mathrm{NMe}_{2}\right)_{4}$ is very sensitive to moisture and can easily decompose in the atmosphere. Use of the two-step ammonolysis process produces a stable intermediate that should be less moisture sensitive.

\section{Results and Discussion}

The SBA-15 functionalized with methyl groups was investigated by Fourier transform infrared spectroscopy (FTIR) using a Perkin-Elmer Spectrum RX I spectrometer. Figure 1 shows the FTIR spectra of calcined and methyl group-functionalized

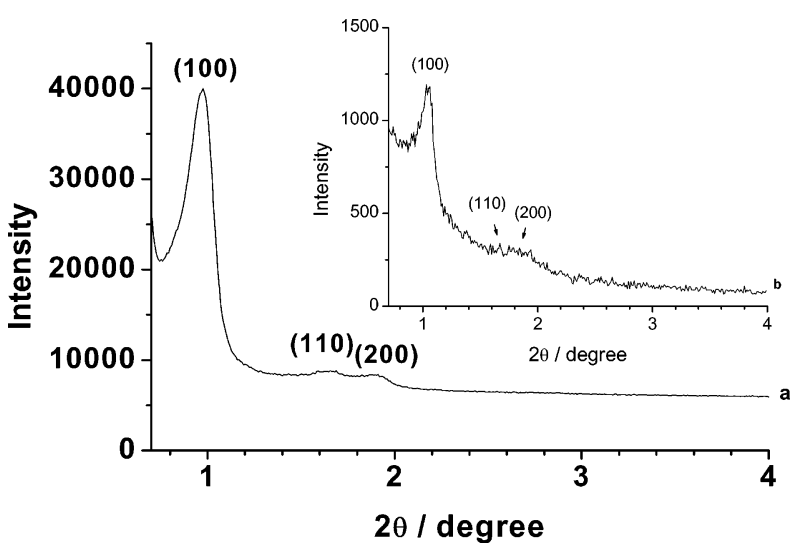

Figure 2. Small-angle powder XRD patterns of (a) calcined SBA-15 and (b) TiN-incorporated SBA-15 heated to $750{ }^{\circ} \mathrm{C}$ for $6 \mathrm{~h}$.

SBA-15 powder. The peaks at 2969 and $1273 \mathrm{~cm}^{-1}$ in the MeSBA-15 sample indicate the presence of $\mathrm{C}-\mathrm{H}$ bonds and $\mathrm{Si}-\mathrm{C}$ bonds, respectively. ${ }^{12,32}$ These peaks show that the pore surface of SBA-15 has been modified with methyl groups that form a hydrophobic layer. The difference in the baseline \% transmittance of the two samples is due to slightly different amounts of SBA-15 samples used in the FTIR measurements.

Retention of high-quality mesoporous SBA-15 after the postsynthesis treatments and the formation of TiN nanostructures can be confirmed by powder X-ray diffraction (XRD) patterns. XRD patterns of the samples were recorded using a Shimadzu XRD-7000 diffractometer with $\mathrm{Cu} \mathrm{K} \alpha$ radiation at $\lambda=1.5418$ $\AA$. Figure $2 \mathrm{a}$ shows the XRD pattern of calcined SBA-15. Strong (100), (110), and (200) diffraction peaks are observed, indicating the presence of long-range order in this sample. The (100) peak is at $0.92^{\circ} 2 \theta$ corresponding to a $d$ spacing of $91.1 \AA$. After the formation of TiN nanostructures inside the SBA-15 sample, the mesoporous framework is maintained (Figure 2b). There is a slight shrinkage of the framework, with the (100) peak shifted to $1.04^{\circ} 2 \theta$, possibly due to a higher degree of silicate condensation during the subsequent high-temperature TiN formation process. Calcined SBA-15 heated to $750{ }^{\circ} \mathrm{C}$ for $6 \mathrm{~h}$ also exhibits the same degree of shrinkage. Figure 3 a shows the high-angle powder XRD pattern of TiN nanostructureincorporated SBA-15 after ammonolysis was performed at 750 


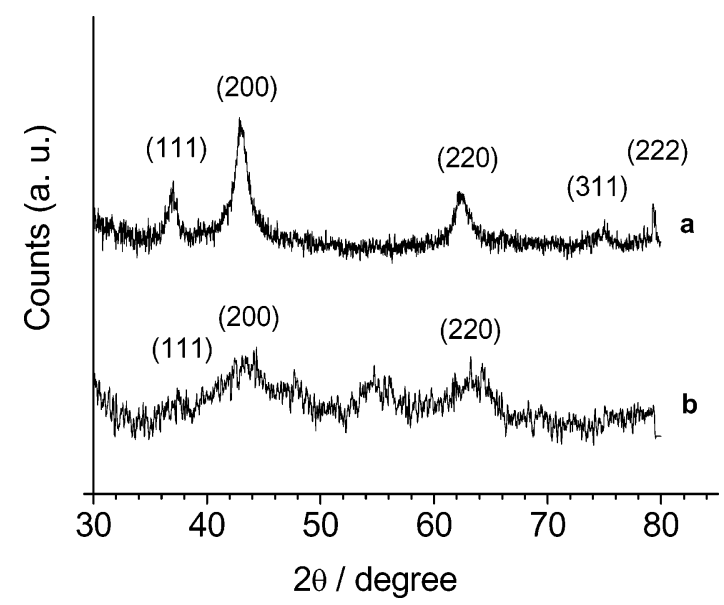

Figure 3. Powder XRD patterns of (a) TiN-incorporated SBA-15 heated to $750{ }^{\circ} \mathrm{C}$ for $6 \mathrm{~h}$ and (b) TiN-incorporated SBA-15 heated to $650{ }^{\circ} \mathrm{C}$ for $1 \mathrm{~h}$.
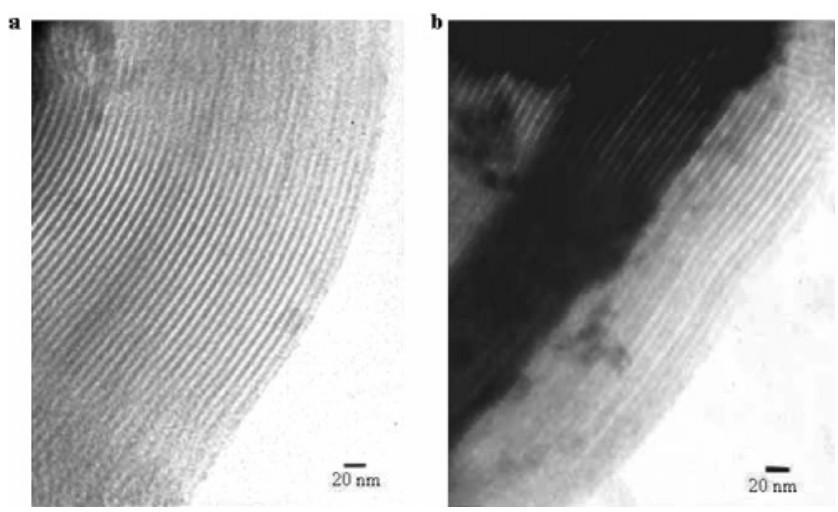

Figure 4. TEM images of (a) calcined SBA-15 and (b) TiNincorporated SBA-15 heated to $750{ }^{\circ} \mathrm{C}$ for $1 \mathrm{~h}$.

${ }^{\circ} \mathrm{C}$ for $6 \mathrm{~h}$. All the expected diffraction peaks for TiN are present, confirming the formation of TiN nanostructures. The estimated TiN particle size, calculated using the Sherrer equation and the measured peak width at half peak height of the (200) peak, ${ }^{33}$ is $\sim 6.5 \mathrm{~nm}$. This number is in close agreement with the average diameter of the channels determined from the nitrogen adsorption-desorption isotherm measurements and the TEM images (discussed later). It may be desirable to form TiN nanoparticles within SBA-15 at lower temperatures. However, ammonolysis at temperatures lower than $700{ }^{\circ} \mathrm{C}$ was found to form only nanocrystalline TiN. Figure $3 \mathrm{~b}$ shows the XRD pattern obtained when the $\mathrm{NH}_{3}$ treatment was carried out at $650{ }^{\circ} \mathrm{C}$ for $1 \mathrm{~h}$. Diffraction peaks for TiN are still present but are very broad and unresolved. The broad peaks centered around 48 and $55^{\circ}$ $2 \theta$ may be due to the presence of a trace amount of rutile and anatase $\mathrm{TiO}_{2}$. A small amount of $\mathrm{Ti}\left(\mathrm{NMe}_{2}\right)_{4}$ may have reacted with the unprotected silanol wall surface at lower temperatures to form $\mathrm{TiO}_{2}$ nanocrystallities. Formation of $\mathrm{TiN}$ through pyrolysis of $\mathrm{TiO}_{2}$ in an ammonia and residual carbon environment at temperatures around $680-1000{ }^{\circ} \mathrm{C}$ has been suggested to proceed by the following reaction: ${ }^{34}$

$$
\mathrm{TiO}_{2}+\mathrm{C}+\mathrm{NH}_{3} \rightarrow \mathrm{TiN}+\mathrm{CO}+\mathrm{H}_{2} \mathrm{O}+0.5 \mathrm{H}_{2}
$$

At $750{ }^{\circ} \mathrm{C}$, the small amount of $\mathrm{TiO}_{2}$ that is present may possibly have been converted into $\mathrm{TiN}$ and thus only $\mathrm{TiN}$ diffraction peaks are observed. However, if the silica wall is not functionalized with methyl groups, strong $\mathrm{TiO}_{2}$, rather than TiN, diffraction peaks may result at $750{ }^{\circ} \mathrm{C}$.
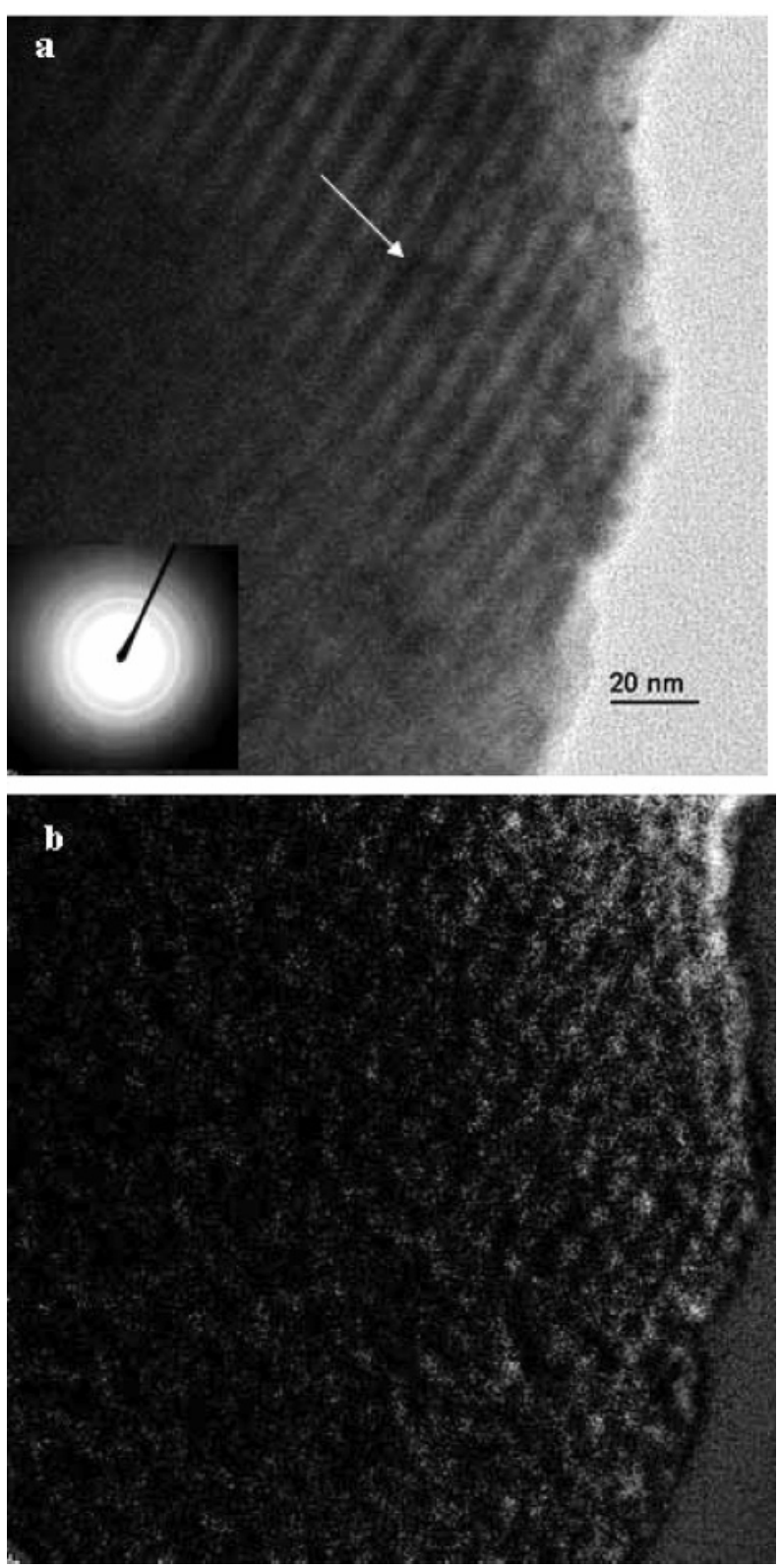

Figure 5. (a) TEM image of an edge portion of a SBA-15 sample with TiN nanoparticles filling the channels. Inset shows the selected area electron diffraction pattern taken over the marked area. (b) EELS elemental mapping of the same area as in (a) showing the locations of $\mathrm{Ti}$ in the sample. Ti shows up as bright dots.

Direct evidence of the formation of TiN nanoparticles within mesoporous silica SBA-15 can be obtained from TEM images of the samples. A JEOL JEM-2010 transmission electron microscope operating at $200 \mathrm{kV}$ was used for the TEM observation. Figure $4 \mathrm{a}$ shows the calcined mesoporous silica SBA-15 with well-defined arrays of nanochannels. The pore diameters are about 5-7 $\mathrm{nm}$. The more diffused areas in the upper and lower portions of this image are observed presumably due to small height differences along the length of the channels making the channels in these areas slightly out of the electron beam focus. Figure $4 \mathrm{~b}$ shows the TEM image of TiNincorporated SBA-15 heated to $750{ }^{\circ} \mathrm{C}$ for $1 \mathrm{~h}$. This image shows clearly the formation of a continuous TiN nanoparticle array extending over several hundreds of $\mathrm{nm}$ in length. The image also reveals that the TiN nanoparticles are well-separated by the silica walls and follow the curvature of the array of channels. The nanoparticles may have been grown to such high 


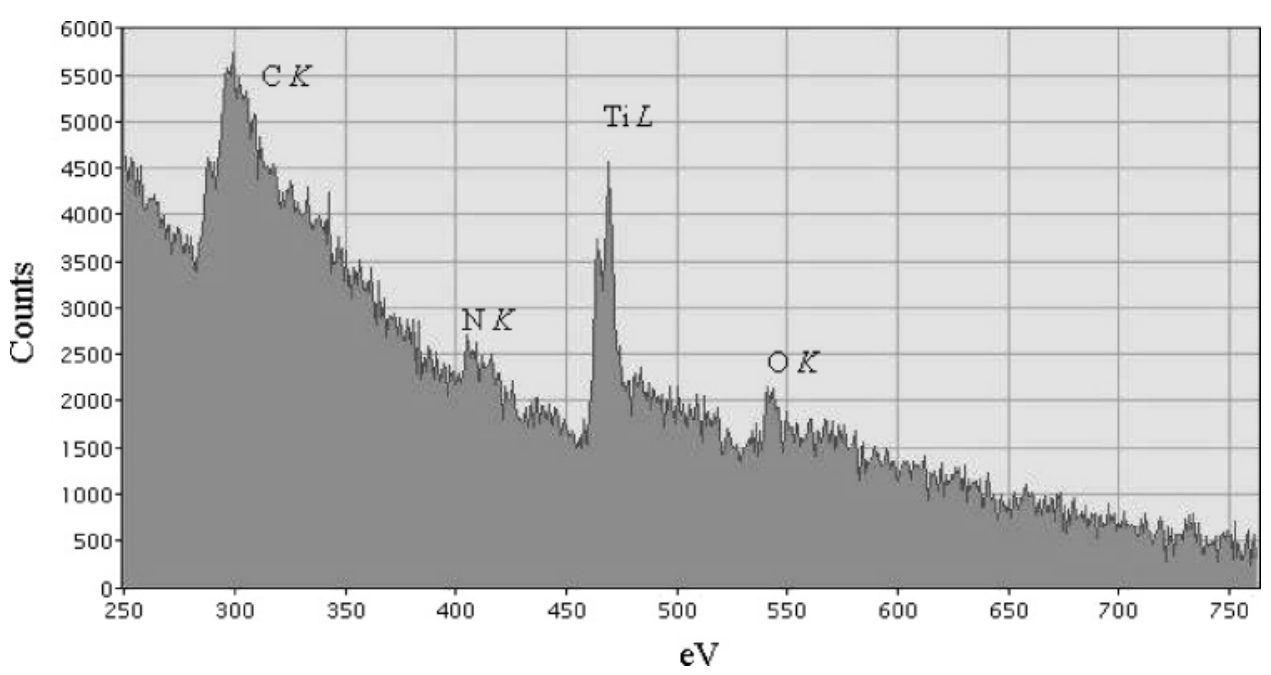

Figure 6. EELS spectrum of the marked region of the sample shown in Figure 5a.

density in some areas that the continuous nanoparticle array appears to form nanowire structure. The confined nanoparticles have a diameter between 5 and $6 \mathrm{~nm}$.

To further confirm that TiN nanoparticles line up along the nanochannels of SBA-15, analytical TEM characterization of the TiN-incorporated sample was performed. A Philips Tecnai 20 transmission electron microscope operating at $200 \mathrm{kV}$ and equipped with electron energy loss spectrometer (EELS) was used for this purpose. Figure 5a shows the TEM image of an edge portion of a TiN-incorporated SBA-15 sample. It can be seen that TiN nanoparticles fill the channels. The selected area electron diffraction (SAED) pattern taken over the marked area of Figure 5a shows a ring pattern. The SAED pattern can be indexed to the (111), (200), (220), (311), (222), (331), (420), and (422) diffraction planes of TiN. The diffraction rings indicate the presence of polycrystalline TiN. EELS elemental mapping of the same sample for Ti is shown in Figure 5b. Bright spots indicate the presence of Ti. It reveals that Ti lines up along the channels, especially near the edge of the sample. Ti distribution becomes less well aligned in the interior of the sample possibly due to unconnected TiN nanoparticles and/or multilayer effects, which may become more important as the sample thickness increases. Figure 6 shows the EELS spectrum of the marked region in Figure 5a. Strong Ti and N signals indicate a high concentration of $\mathrm{TiN}$ nanostructures in the mesoporous SBA-15. The carbon signal presumably is derived from the carbon support film of the TEM grid.

The degree of TiN nanoparticle filling was examined using nitrogen adsorption-desorption isotherm measurements. The nitrogen adsorption-desorption isotherm study was performed at $77 \mathrm{~K}$ using a Micromeritics ASAP 2010 system. Figure 7a shows the nitrogen adsorption-desorption isotherm results for Me-SBA-15 and TiN-incorporated SBA-15 heated at $750{ }^{\circ} \mathrm{C}$ for $1 \mathrm{~h}$. Table 1 gives the values of BET surface areas, total pore volumes, and pore diameters for calcined SBA-15, MeSBA-15, and TiN-incorporated SBA-15 samples. A significant decrease in all the values for the Me-SBA-15 is reasonable, considering the formation of an additional silicate-methyl group layer coating the interior surface of the channels of calcined SBA-15 sample. A considerable decrease in the total pore volume due to the incorporation of $\mathrm{TiN}$ nanoparticles was measured; the total pore volume dropped from $0.53 \mathrm{~cm}^{3} \mathrm{~g}^{-1}$ for the Me-SBA-15 to $0.25 \mathrm{~cm}^{3} \mathrm{~g}^{-1}$ after the incorporation of TiN nanostructures. This result suggests that a high degree of TiN nanoparticle loading occurred in the TiN-incorporated SBA15 sample. The weight percentage loading of TiN was calculated
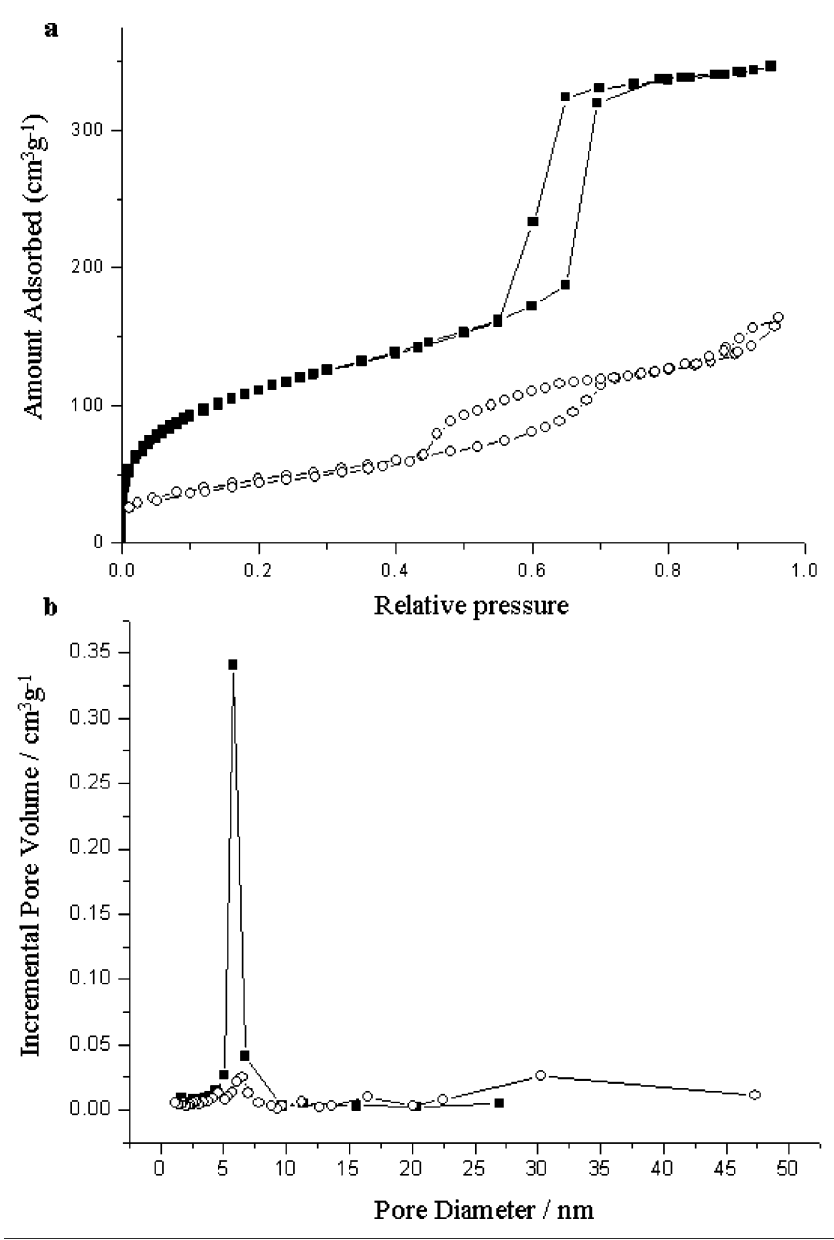

Figure 7. (a) Nitrogen adsorption-desorption isotherms of methyl group-functionalized SBA-15 (black squares) and TiN-incorporated SBA-15 heated to $750{ }^{\circ} \mathrm{C}$ for $1 \mathrm{~h}$ (open circles). (b) Pore size distribution of the same samples calculated from the adsorption branch of the isotherms using the $\mathrm{BJH}$ algorithm.

to be about $33 \%$. This can be done by first considering the relative volumes of the nanochannels to that of the TiNincorporated SBA-15 framework. These values can be determined by considering a hexagonal unit cell in the TiNincorporated SBA-15 powder with a pore diameter of $6.1 \mathrm{~nm}$ and an edge length of the hexagon $a_{0}$ of $98.1 \AA$, where $a_{0}=2$ $\times d_{(100)} / \sqrt{ } 3 .{ }^{3 a}$ Calculations show that $35.06 \%$ of the SBA-15 volume is occupied by the pore channels. Using the total pore 
TABLE 1: Physical and Surface Properties of Selected Samples

\begin{tabular}{lccc}
\hline \multicolumn{1}{c}{ sample } & $S_{\mathrm{BET}} / \mathrm{m}^{2} \mathrm{~g}^{-1}$ & $V_{\mathrm{t}} / \mathrm{cm}^{3} \mathrm{~g}^{-1}$ & $D_{\mathrm{BJH}} / \mathrm{nm}$ \\
\hline SBA-15 & 740 & 0.87 & 7.0 \\
Me-SBA-15 & 399 & 0.53 & 5.9 \\
TiN-SBA-15 $\left(750{ }^{\circ} \mathrm{C}\right.$ for $\left.1 \mathrm{~h}\right)$ & 168 & 0.25 & 6.1
\end{tabular}

${ }^{a} S_{\mathrm{BET}}$, BET specific surface area; $V_{\mathrm{t}}$, total pore volume; $D_{\mathrm{BJH}}$, pore diameter calculated using the $\mathrm{BJH}$ method.

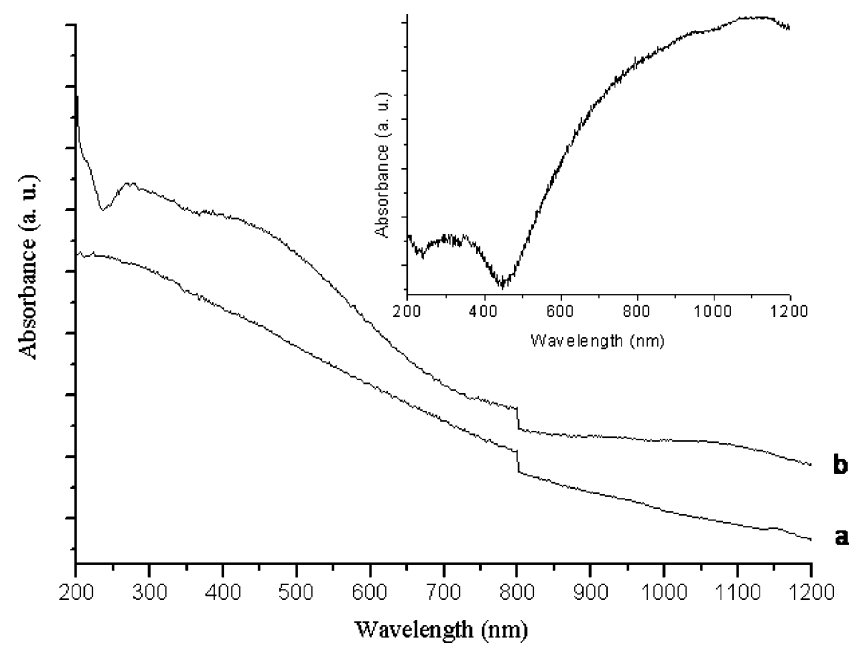

Figure 8. UV-vis absorption spectra of (a) calcined SBA-15 and (b) TiN-incorporated SBA- 15 heated to $750{ }^{\circ} \mathrm{C}$ for $6 \mathrm{~h}$. The discontinuity in the absorbance at $\sim 800 \mathrm{~nm}$ is due to grating/detector change. Inset shows the UV-vis absorption spectrum of fine TiN powder. For each measurement, a very small amount of the powder sample was added to deionized water to form a dilute aqueous suspension.

volume results from the nitrogen adsorption-desorption isotherm measurements, the relative volume percentages of TiN (11.3\%), $\mathrm{SiO}_{2}$ (64.94\%), and the methyltriethoxysilane layer $(13.7 \%)$ can be known. The weight percentage of TiN loading can then be obtained by calculating the ratio of the mass of TiN (volume multiplied by density) to the sum of the masses of $\mathrm{SiO}_{2}$ and methyltriethoxysilane, assuming methyltriethoxysilane remains intact for the ease of calculations. Although the TiN loading data may be obtained by elemental analysis, the presence of some TiN nanoparticles residing outside the SBA15 powder and some powder without any TiN nanostructure incorporation may make the results less reliable. Figure $7 \mathrm{~b}$ shows that the pore diameter is $\sim 6 \mathrm{~nm}$, which is consistent with that measured from the TEM images. The pore size distribution plot also shows that the TiN-incorporated SBA-15 sample contains pores in the $30 \mathrm{~nm}$ range. This extremely large pore size is attributed to the aggregated porous structure of TiN nanoparticles formed outside the SBA-15 powder. ${ }^{29}$

UV-vis absorption spectra of the TiN-incorporated SBA15 samples may be used to provide additional evidence of the formation of TiN nanostructures within the channels of SBA15 powder and reveal unique optical properties. A JASCO V-570 UV/VIS/NIR spectrophotometer was used for the measurements. Figure 8a shows the UV-vis absorption spectrum of calcined SBA-15. A spectrum with a nearly linear and continuous decrease in absorbance was recorded. Figure $8 \mathrm{~b}$ shows the absorption spectrum of TiN-incorporated SBA-15 heated to $750{ }^{\circ} \mathrm{C}$ for $6 \mathrm{~h}$. A continuous absorbance decrease in the higher wavelength region was obtained, which is similar to that observed for the calcined SBA-15 sample. Two additional broad bands centered at around 280 and $425-450 \mathrm{~nm}$ were also observed. To assist in the interpretation of these results, the UV-vis absorption spectrum of fine TiN powder (Aldrich, $<10$ $\mu \mathrm{m}, 99 \%$ ) was taken and the result is shown in the inset of Figure 8 . There is a broad UV band centered at around $320 \mathrm{~nm}$ and then the absorbance increases sharply from $\sim 450 \mathrm{~nm}$ to the NIR region. Judging from the obvious differences in absorbance characteristics in the visible and NIR regions between the TiN-incorporated SBA-15 sample and the fine TiN powder sample, the results suggest that the TiN nanostructures are confined in the channels of SBA-15 and that no large TiN particles are formed outside or on the surface of SBA-15. On the basis of the similar broad band feature and the close proximity of the absorption bands in the UV region for both the TiN-incorporated SBA-15 and the fine TiN powder samples, the appearance of this UV band in TiN-incorporated SBA-15 may be attributed to the presence of TiN nanoparticles. In this regard UV-vis absorption spectroscopy can be a useful tool for the preliminary characterization of the formation of TiN nanostructures within mesoporous silica materials. The broad band centered at $\sim 425-450 \mathrm{~nm}$ appears to be a new absorption feature only observed in the TiN-incorporated SBA-15 samples. Quinten has discussed by theoretical calculations the exhibition of a surface plasmon resonance band centered at $\sim 500 \mathrm{~nm}$ for monosized spherical TiN nanoparticles. ${ }^{35}$ Although the nature for the appearance of this broad band is still not clear, the fact that the broad band covers the $500 \mathrm{~nm}$ region suggests that this band may be associated with the surface plasmon resonance absorption of the TiN nanoparticles. The position of this band is blue-shifted from the $500 \mathrm{~nm}$ center, as theoretically predicted for spherical nanoparticles, possibly due to the elongated shapes of the TiN nanoparticles confined in channels of SBA-15. Of course, TiN nanoparticles $(\sim 10-30 \mathrm{~nm}$ in diameter) observed outside SBA-15 may contribute to the overall absorption. Further work is required to determine the exact nature of this unique optical feature.

\section{Conclusion}

In summary, the synthesis of TiN nanoparticles inside the channels of mesoporous silica SBA-15 has been demonstrated. $\mathrm{Ti}\left(\mathrm{NMe}_{2}\right)_{4}$ was used as the TiN precursor and introduced into the nanoscale channels of methyl group-modified SBA-15 in toluene under an ammonia flow at $700-750{ }^{\circ} \mathrm{C}$ for $1-6 \mathrm{~h}$. Powder XRD patterns, TEM images, EELS elemental mapping and spectrum, and nitrogen adsorption-desorption isotherm measurements have verified the formation of TiN nanoparticles within mesoporous SBA-15. UV-vis absorption spectra have also been used to characterize the resulting material. A unique optical feature has been observed and may be related to the surface plasmon resonance absorption of $\mathrm{TiN}$ nanoparticles confined in the channels of SBA-15. The new synthetic approach may find applications in semiconductor fabrication design and high-temperature materials preparation. It is envisioned that other binary nitride nanoparticles may be formed within mesoporous silica by using a preparation approach similar to that described in this study.

Acknowledgment. This work was supported by a grant from the National Science Council of Taiwan (NSC 91-2119-M-007006) and the start-up fund provided by the Department of Chemistry at National Tsing Hua University. We thank ChienYang Chiu and Wei-Kuo Chang for assistance in the nitrogen physisorption measurements. We also thank Prof. Hong-Yi Tang for assistance in the powder XRD pattern measurements. Jeffrey I. Zink thanks the U.S. NSF grant (DMR 0103952).

\section{References and Notes}

(1) (a) Cai, Q.; Lin, W. Y.; Xiao, F. S.; Pang, W. Q.; Chen, X. H.; Zou, B. S. Microporous Mesoporous Mater. 1999, 32, 1. (b) Kresge, C. T. 
Leonowicz, M. E.; Roth, W. J.; Vartuli, J. C.; Beck, J. S. Nature 1992, 359, 710. (c) Beck, J. S.; Vartuli, J. C.; Roth, W. J.; Leonowicz, M. E.; Kresge, C. T.; Schmitt, K. D.; Chu, C. T.-W.; Olson, D. H.; Sheppard, E. W.; McCullen, S. B.; Higgins, J. B.; Schlenker, J. L. J. Am. Chem. Soc. 1992, 114, 10834

(2) (a) Ryoo, R.; Joo, S. H.; Kim, J. M. J. Phys. Chem. B 1999, 103, 7435. (b) Kruk, M.; Jaroniec, M.; Ryoo, R.; Joo, S. H. Chem. Mater. 2000 12, 1414. (c) Morey, M. S.; Bryan, J. D.; Schwarz, S.; Stucky, G. D. Chem. Mater. 2000, 12, 3435. (d) Huo, Q.; Marolese, D. I.; Stucky, G. D. Chem. Mater. 1996, 8, 1147.

(3) (a) Zhao, D.; Feng, J.; Huo, Q.; Melosh, N.; Fredrickson, G. H.; Chmelka, B. F.; Stucky, G. D. Science 1998, 279, 548. (b) Zhao, D.; Huo, Q.; Feng, J.; Chmelka, B. F.; Stucky, G. D. J. Am. Chem. Soc. 1998, 120 6024.

(4) Kim, S.; Son, S.; Lee, S. I.; Hyeon, T.; Chung, Y. K. J. Am. Chem. Soc. 2000, 122, 1550

(5) Winkler, H.; Birkner, A.; Hagen, V.; Wolf, I.; Schmechel, R.; von Seggern, H.; Fisher, R. A. Adv. Mater. 1999, 11, 1444.

(6) Xu, W.; Liao, Y.; Akins, D. L. J. Phys. Chem. B 2002, 106, 11127

(7) Zhang, W.-H.; Shi, J.-L.; Chen, H.-R.; Hua, Z.-L.; Yan, D.-S. Chem. Mater. 2001, 13, 648 .

(8) Fukuoka, A.; Sakamoto, Y.; Guan, S.; Inagaki, S.; Sugimoto, N.; Fukushima, Y.; Hirahara, K.; Iijima, S.; Ichikawa, M. J. Am. Chem. Soc. 2001, 123, 3373.

(9) Huang, M. H.; Choudrey, A.; Yang, P. Chem. Commun. 2000, 1063.

(10) Han, Y.-J.; Kim, J. M.; Stucky, G. D. Chem. Mater. 2000, 12, 2068

(11) Wang, L.-Z.; Shi, J.-L.; Zhang, W.-H.; Ruan, M.-L.; Yu, J.; Yan, D.-S. Chem. Mater. 1999, 11, 3015.

(12) Yang, C.-M.; Liu, P.-H.; Ho, Y.-F.; Chiu, C.-Y.; Chao, K.-J. Chem. Mater. 2003, 15, 275 .

(13) Yang, C.-M.; Sheu, H.-S.; Chao, K.-J. Adv. Funct. Mater. 2002 , 12,143 .

(14) Shin, H. J.; Ko, C. H.; Ryoo, R. J. Mater. Chem. 2001, 11, 260

(15) Liu, Z.; Sakamoto, Y.; Ohsuna, T.; Hiraga, K.; Terasaki, O.; Ko,

C. H.; Shin, H. J.; Ryoo, R. Angew. Chem., Int. Ed. 2000, 39, 3107.

(16) Shin, H. J.; Ryoo, R.; Liu, Z.; Terasaki, O. J. Am. Chem. Soc. 2001 123,1246

(17) Lee, K.-B.; Lee, S.-M.; Cheon, J. Adv. Mater. 2001, 13, 517.

(18) Zhang, Z.; Dai, S.; Blom, D. A.; Shen, J. Chem. Mater. 2002, 14 965.

(19) Luan, Z.; Maes, E. M.; van der Heide, P. A. W.; Zhao, D.; Czernuszewicz, R. S.; Kevan, L. Chem. Mater. 1999, 11, 3680.
(20) (a) Kónya, Z.; Puntes, V. F.; Kiricsi, I.; Zhu, J.; Alivisatos, A. P. Somorjai, G. A. Nano Lett. 2002, 2, 907. (b) Kónya, Z.; Puntes, V. F.; Kiricsi, I.; Zhu, J.; Ager, J. W., III; Ko, M. K.; Frei, H.; Alivisatos, P.; Somorjai, G. A. Chem. Mater. 2003, 15, 1242.

(21) Wang, D.; Zhou, W. L.; McCaught, B. F.; Hampsey, J. E.; Ji, X.; Jiang, Y.-B.; Xu, H.; Tang, J.; Schmehl, R. H.; O'Connor, C.; Brinker, C. J.; Lu, Y. Adv. Mater. 2003, 15, 130.

(22) Fukuoka, A.; Araki, H.; Sakamoto, Y.; Sugimoto, N.; Tsukada, H.; Kumai, Y.; Akimoto, Y.; Ichikawa, M. Nano Lett. 2002, 2, 793.

(23) Besson, S.; Gacoin, T.; Ricolleau, C.; Jacquiod, C.; Boilot, J.-P. Nano Lett. 2002, 2, 409.

(24) Zhang, Z.; Dai, S.; Fan, X.; Blom, D. A.; Pennycook, S. J.; Wei, Y. J. Phys. Chem. B 2001, 105, 6755.

(25) Parala, H.; Winkler, H.; Kolbe, M.; Wohlfart, A.; Fischer, R. A.; Schmechel, R.; von Seggern, H. Adv. Mater. 2000, 12, 1050.

(26) Zhang, W.-H.; Shi, J.-L.; Wang, L.-Z.; Yan, D.-S. J. Am. Chem. Soc. 2000, 12, 1408.

(27) Agger, J. R.; Anderson, M. W.; Pemble, M. E.; Terasaki, O.; Nozue, Y. J. Phys. Chem. B 1998, 102, 3345 .

(28) Srdanov, V. I.; Alxneit, I.; Stucky, G. D.; Reaves, C. M.; DenBaars, S. M. J. Phys. Chem. B 1998, 102, 3341.

(29) Kaskel, S.; Schlichte, K.; Chaplais, G.; Khanna, M. J. Mater. Chem. 2003, 13, 1496.

(30) Raaijmakers, I. J. Thin Solid Films 1994, 247, 85.

(31) (a) Cheon, J.; Guile, M.; Muraoka, P.; Zink, J. I. Inorg. Chem. 1999, 38, 2238. (b) Weiler, B. H. J. Am. Chem. Soc. 1996, 118, 4975. (c) Cundari, T. R.; Morse, J. M. Chem. Mater. 1996, 8, 189. (d) Katz, A.; Feingold, A.; Nakahara, S.; Pearton, S. J.; Lane, E.; Geva, M.; Stevie, F. A.; Jones, K. J. Appl. Phys. 1992, 71, 993. (e) Katz, A.; Feingold, A.; Pearton, S. J.; Nakahara, S.; Ellington, M.; Chakrabarti, U. K.; Geva, M.; Lane, E. J. Appl. Phys. 1991, 70, 3666.

(32) (a) Chen, J. Y.; Pan, F. M.; Cho, A. T.; Chao, K. J.; Tsai, T. G.; Wu, B. W.; Yang, C. M.; Chang, L. J. Electrochem. Soc. 2003, 150, F123. (b) de Theije, F. K.; Balkenende, A. R.; Verheijen, M. A.; Baklanov, M. R.; Mogilnikov, K. P.; Furukawa, Y. J. Phys. Chem. B 2003, 107, 4280.

(33) West, A. R. Solid State Chemistry and its Applications; John Wiley \& Sons: New York, 1992; pp 173-175.

(34) (a) Jiang, Z.; Rhine, W. E. Chem. Mater. 1991, 3, 1132. (b) Brinker,

C. J.; Haaland, D. M. J. Am. Ceram. Soc. 1983, 66, 758 .

(35) Quinten, M. Appl. Phys. B 2001, 73, 317. 